\title{
La historiografía actual desde 1989
}

\section{Present historiography from 1989}

\author{
Juan Manuel SANTANA-PÉREZ \\ Universidad de Las Palmas de Gran Canaria \\ juanmanuel.santana@ulpgc.es \\ Israel SANMARTín BARROS \\ Universidad de Santiago de Compostela \\ israel.sanmartin@usc.es
}

Fecha de recepción: 08-02-2019

Fecha de aceptación: 20-10-2019

\section{RESUMEN}

La historia como disciplina social ha sido condicionada por discursos políticos y económicos triunfantes que se han convertido en una nueva ideología. Esto se recrudeció tras la caída del Muro de Berlín y la consiguiente desintegración del sistema soviético y del mundo polarizado este-oeste. Este hecho supuso un cambio importante en las relaciones internacionales y en el pensamiento político a nivel planetario. La teoría de la historia se vio fuertemente sacudida por estas transformaciones pero el embate fue más fuerte para la "historia crítica" que seguía la tradición de Annales y del materialismo histórico. Tras unos primeros años de desconcierto se ha ido reformulando con las mejores aportaciones del siglo XX y las innovaciones epistemológicas y empíricas del siglo XXI.

Palabras clave: Teoría de la Historia, Globalización, Neoconservadurismo, Historia Crítica, Posmodernidad, Presentismo filosófico

Período: fin de siglo XX-XXI.

\section{ABSTRACT}

History as a social discipline has been conditioned by political discourse and economic globalization that is fast becoming a new ideology. The fall of the Berlin Wall led to the disintegration of of the Soviet Union and the polarized East-West world. This was accompanied by a significant change in international relations and political thought at a global level. The theory of history was shaken by these transformations but they had a greater impact upon "critical history", which followed the tradition of Annales and historical materialism. After these early years of turbulence, it has been reformulated with the best $20^{\text {th }}$ century contributions and the epistemological and empirical innovations of the 21st century.

Key words: Theory of History, Globalization, Neo-conservative, Critic History, Postmodernism, Philosophical Presentism,

Period: end of the 20th-21th century. 


\section{INTRODUCCIÓN}

El presente artículo parte de la idea del cambio que supuso para la historiografía la fecha de 1989 y sus dimensiones históricas e historiográficas. Tal como ha afirmado Eric Hobsbawm, el siglo XXI comenzó en $1991^{1}$. Una fecha que dio punto de partida a la conformación de un nuevo mundo con unas características históricas diferentes al periodo anterior, no en cuanto a un cambio radical de la esfera de las relaciones sociales de producción, pero sí en relación a cambios políticos, culturales, tecnológicos, de producción económica y de nuevo "orden" internacional. El 9 de noviembre de 1989 los alemanes derribaron el muro de Berlín que habían construido en 1961 y ello precipitó la desintegración del mundo soviético en 1991. Esto tuvo repercusiones directas para toda la Europa centro-oriental y para el conjunto de las ideologías de todo el planeta. El nuevo escenario, caracterizado por la hegemonía del capital financiero y especulativo, no es cuestionado por casi nadie, al contrario, se presenta como la panacea deseable, en medio de un proceso caracterizado por la intensa ampliación de las áreas geográficas de libre intervención del capital. Así, hubo un marxismo que murió aplastado por el Muro, pero también otro consciente de la necesidad de enfrentarse a un mundo cambiante, que obliga a formular nuevas cuestiones a la historia y a retomar problemas que, en otro momento, habían sido considerados secundarios.

Con este marco, abordaremos los cambios que ha sufrido la historia desde ese momento. Para ellos, haremos una primera aproximación contextual al marco teórico que surge en el siglo XXI. Luego haremos un análisis de las herencias metodológicas que han pervivido a nivel conceptual y de escuelas historiográficas para inmediatamente abordar el estudio de las novedades historiográficas que han surgido en los últimos años. Por último, plantearemos una serie de retos y debates que pueden marcar la agenda de algunos historiadores del siglo XXI y abordaremos unas conclusiones.

\section{LA CONFIGURACIÓN DEL MARCO TEÓRICO DE LA HISTORIOGRAFÍA DEL SIGLO XXI}

Al finalizar la Guerra Fría dos teorías fueron formuladas: el "fin de la historia" de Francis Fukuyama y el "choque de civilizaciones" de Samuel Huntington. Ambas tesis dieron pie a dos pensamientos cada vez menos cuestionados. El primero es que había triunfado el modelo capitalista neoliberal en contraposición al supuestamente comunista, y el segundo que el mundo tendía a la unilateralidad hegemónica de los Estados Unidos. Estos postulados, concordantes con la teoría del Fin de la Historia formulada en 1992, hacían de Fukuyama el pensador que anticipara las claves para la interpretación de las relaciones internacionales y el nuevo orden mundial. En contraposición, la teoría del choque de civilizaciones, formulada por Samuel P. Huntington sólo un año más tarde, quedaba en un segundo plano.

Huntington vino a contradecir la idea del fin de la historia, trató de ordenar el caos del denominado nuevo orden internacional, buscando la clave de todo en las civilizaciones. Entiende por civilización una entidad cultural que aúna pueblos, regiones, grupos étnicos, nacionalidades y grupos religiosos de distintos niveles de heterogeneidad cultural². El concepto de civilización se refiere a hechos muy diversos, pero como ha señalado Norbert Elias, podemos llegar a la conclusión de que este concepto expresa la autoconciencia de Occidente, es decir, resume

1 E. Hobsbawm, Entrevista sobre el siglo XXI, Barcelona, Crítica, 2000.

2 Huntington se inspiró en Toynbee y en Braudel para utilizar el concepto de civilizaciones, aunque pretendió resumirlas en este momento histórico con una objetividad todavía más dudosa que en esos historiadores. J. Goberna, Civilización. Historia de una idea, Santiago de Compostela, Universidad de Santiago de Compostela, 1999, pp. 261-262. 
todo aquello que la sociedad occidental de los últimos dos o tres siglos cree llevar de ventaja a las sociedades anteriores o a las contemporáneas "más primitivas"3.

Afirmar que la Historia de la Humanidad es la Historia de las Civilizaciones es la manifestación de un gran cambio teórico que comenzó por criticar el simplismo economicista de un materialismo histórico dogmático. Es la primacía de la cultura o civilización, que aparecen como sinónimos hasta desembocar en la negación no ya de la economía, sino de las relaciones sociales de producción que desaparecen de la interpretación del mundo, quedando todo reducido a una culturalidad desvinculada del conjunto de la realidad que enmascara todos los aspectos sociales.

Paralelamente a esto, tras la caída del Muro de Berlín hubo un gran debate en torno al marxismo, que ha cristalizado en diferentes propuestas, incluso el de enterrarlo, de la que forma parte la tesis de Fukuyama. De todas formas, surgió una nueva sociedad civil global que ha dado lugar a un movimiento altermundista y a un pensamiento crítico que ha servido, al menos, para realizar nuevas revisitaciones al marxismo ${ }^{4}$. Incluso esto provocó una expansión del antimarxismo. Hablar de "fin de la Historia" significa apelar a la teleología y discurso narrativo, y en definitiva hablar de fin del marxismo como verdad coherente y verosímil. Daniel Bell entendía que el marxismo estaba acabado o iba camino de desaparecer, y citaba a la Europa del Este, África o China como ejemplos ${ }^{5}$. En el contexto de la caída del Muro de Berlín, V. G. Kiernan denunciaba que el marxismo subestimó la capacidad expansiva de la producción capitalista. Y citaba que se había tenido poco en cuenta a Engels, en el sentido de que los resultados no concuerdan nunca con las previsiones. Por tanto, la historia sólo puede discurrir zigzageante, no linealmente, y sin perder de vista que muchos de sus resultados no son queridos por nadie ${ }^{6}$. Frente a esto, hay que considerar que el marxismo también sobrevaloró la simplicidad de las revoluciones como respuestas al cambio económico y a las necesidades humanas en épocas en las que el orden político había sido incapaz de adaptarse a los cambios correspondientes en las relaciones sociales.

La guerra de Irak (apoyada por el Gobierno español en un primer momento), el surgimiento de la nueva izquierda latinoamericana y la gran crisis económica que comenzó en el año 2007 y que todavía está en curso, fueron reforzadas por otros acontecimientos para conformar un nuevo orden internacional que viene a ser la extensión de lo que ya se había venido practicando en el siglo XX en América Latina y que ahora con el "mundo globalizado" se extiende a todo el planeta. Estos cambios han traído consigo una reorientación de todas las ciencias sociales en general y, particularmente, de la Historia. La teoría de la Historia siempre se ha visto fuertemente influenciada por todos los acontecimientos políticos, económicos y sociales. Estas teorías conservadoras que consagran el sistema capitalista y la democracia representativa han irrumpido en el siglo XXI como una nueva ideología y como un nuevo marco epistémico para la historia.

3 N. Elias, El proceso de civilización. Investigaciones sociogenéticas y psicogenéticas, Madrid, Fondo de Cultura Económica, 1993, p. 57.

4 Sobre las corrientes marxistas en el siglo XX tanto en Occidente como en otros lugares ver $\mathrm{G}$. Therborn, "Dialectics of Modernity: On Critical Theory and the Legacy of Twentieth-Century Marxism", New Left Review, 215 (Jan/feb 1996), pp. 59-81.

5 D. Bell, "Choque de civilizaciones", El País, sábado 6 de agosto de 1994, pp. 9-10.

6 V. G. Kiernan, "Marxismo y revolución" en A propósito del fin de la historia, Valencia, Edicions Alfons el Magnànim, 1994, pp. 53-54. 


\section{LA IMPORTANCIA DE LA METODOLOGÍA EN EL CONTEXTO DE LA (DES) GLOBALIZACIÓN}

En la historiografía actual estamos asistiendo a la vuelta del protagonismo de los acontecimientos y de los cambios realizados en el día a día. Después de 1989 estos eventos se han acelerado ${ }^{7}$ y todo transcurre mucho más deprisa de lo que resulta factible controlar. Por otro lado, después de la caída del Muro de Berlín, ha habido una reorganización de la economía mundial en las últimas décadas, caracterizada por la creciente globalización de los mercados, particularmente el financiero. No se puede decir lo mismo de los mercados de bienes y servicios ni del trabajo (de hecho se endurecen las leyes de inmigración en los países centrales), así como del fortalecimiento de los grandes bloques comerciales. En realidad no es más que una mundialización del capital; ni siquiera podemos hablar de una mundialización económica ${ }^{8}$.

Todos estos cambios que se van produciendo en la economía mundial tienen como telón de fondo el auge que, desde el punto de vista teórico y su instrumentación práctica, cobra el neoliberalismo. Esto ha dado lugar a que a menudo se confunda globalización con neoliberalismo y se vean como fenómenos idénticos. Sin embargo, consideramos que la globalización es un proceso de carácter histórico y que ha sido posible gracias a los importantes avances de la tercera revolución científico-técnica. Por su parte, el neoliberalismo es una política económica, una ideología que se disfraza de "no ideología", y que tiene un carácter transitorio y reversible. En este sentido, los propios discursos sobre la presunta crisis de la historia constituyen una verdadera ideología ${ }^{9}$.

Este modelo, combinado con la aplicación de políticas neoliberales ha traído como consecuencia una mayor profundización de la marginación y la exclusión. Incluso se puede apreciar que los propios países del llamado primer mundo comienzan a tener dentro su propio Tercer Mundo. En ese contexto, algunos elementos se han convertido en estructurales. Por ejemplo, el paro, que se ha convertido en un fenómeno permanente. La globalización ha hecho posible la descentralización de este proceso. Pero ha conseguido que avance la acumulación y la centralización del capital. Esto ha afectado a los Estados nacionales, en los que se ha profundizado la polarización entre regiones y los sectores, lo que ha generado el descontento de las nacionalidades presuntamente "ahistóricas", lo que es una aberración en sí mismo. Muchos han tildado este proceso como de "desglobalización"10, idea surgida a raíz de la movilización de la sociedad civil global altermundista ${ }^{11}$, que últimamente ha sido también reforzada por ideas como la "renta básica universal" o el "decrecimiento"12.

En este contexto, algunos historiadores que creían tener todas las respuestas al pasado conflictivo y que hallaban las leyes inexorables del futuro, se han sumergido en el neopositivismo y en hacer una "Historia de mojones" a la caza de subvenciones y efemérides. El fin es hacer una historia que construya las identidades que el sistema necesita. Otros investigadores, sin embargo, se han dedicado a indagar en aspectos de la realidad cultural que antes quedaban abandonados por no estar en la esencia de la infraestructura, y ahora se han sumado a la curiosidad histórica. De este modo, en no pocos casos, lo escabroso

7 I. Sanmartín, Entre dos siglos. Globalización y pensamiento único, Madrid, Akal, 2007, p. 293.

8 J. M. Santana, "Globalization and Historiography" en C. Barros y L. McCrank (eds.), History under Debate. International Reflexion on the Discipline, New York, The Harworth Press, inc, pp. 107-127.

9 I. Dubert, "A crise historiográfica como ideoloxía", en C. Barros (ed.) Historia a debate: Galicia, Santiago de Compostela, Historia a Debate, 1995, pp. 31-46.

10 W. Bello, Desglobalización. Ideas para una nueva economía mundial, Barcelona, Icaria, 2004.

11 J. Pastor, Qué son los movimientos antiglobalización, Barcelona, RBA, 2002.

12 C. Taibo, El decrecimiento explicado con sencillez, Madrid, Los Libros de la Catarata, 2011. 
y lo lúdico se han incorporado avasalladoramente a la Historia, pero constreñidos por una serie de limitaciones epistemológicas que muchas veces los reducen a la condición de amena recuperación de las curiosidades del pasado para disfrute masivo de la sociedad de consumo ${ }^{13}$.

\subsection{Las Continuidades en el oficio de historiador después de 1989}

Los seguidores de Fukuyama se colocaban en el punto de vista del historicismo de Ranke, quien aseveró que el individuo histórico por excelencia es el Estado. Y como individuo, se relacionaba con otros individuos, con otros Estados. De aquí uno de los principios fundamentales de la historiografía alemana, que es el primado de la política exterior. Las distintas constelaciones de Estados, en hegemonía o equilibrio, forman una unidad y una época. Esto es lo que se derrumba en 1989. Pero aun andaban calientes las máquinas de sus imprentas proclamando ese fin, cuando comienza la Guerra del Golfo (1991). Ahora no era entre Estados dominadores, sino entre el mundo rico y la periferia. Es decir, de nuevo era la misma contradicción de siempre. Por eso, pensamos que la historia del siglo XXI ha mantenido las siguientes características:

a) La importancia de la teoría. En la historia del siglo XXI la teoría debe seguir siendo una parte importante, porque es necesario tener sólidos los fundamentos teóricos y epistemológicos sobre los que descansa la indagación de nuevos temas, sin caer en la radicalidad posmoderna de negar una concepción unificadora de niveles de la realidad (social, político, mental, económico, etc.). Los fundamentos teóricos no pueden ser comprendidos de forma aislada en los procesos históricos, pero sí se pueden superar los apriorismos frecuentes de la tradición historiográfica y de los "grandes relatos de emancipación" que formaban identidades (con "gran relato" nos referimos a un objetivo final que justifica lo que hacemos para lograr ese fin). De esta forma, se revierte la situación creada a partir de la propuesta de algunos historiadores que propugnaban una cierta "desteorización" de la historia ${ }^{14}$. La teoría subraya una práctica histórica y legitima un programa epistémico en desde un posicionamiento claro ${ }^{15}$.

b) La conexión de la teoría con la práctica. No hay que perder de vista la realidad, nuestras teorías nos sirven para explicar esa realidad, y si no concuerda, hay que cambiar la explicación, con una absoluta objetividad sobre los datos, lo que no implica neutralidad; aunque sí alejarse de aquellas historias oficiales que eliminaban o deformaban episodios enteros del pasado, cuyos resultados fueron nefastos.

c) La importancia de los datos y los acontecimientos. En este sentido, es importante incidir en la reivindicación del trabajo de archivo y documentación por parte del historiador. Es necesaria la base empírica y demostrar con las fuentes documentales las afirmaciones, para no caer en los mecanicismos típicos de otras épocas ${ }^{16}$, muchas veces procedentes de teóricos no historiadores, que con un lúcido esquema creían tener todas las respuestas, donde todo encajaba. Para llegar a nuestras formulaciones teóricas es preciso dedicar muchas horas a estudios empíricos de los diversos problemas históricos que nos planteamos resolver; es decir, que todos los historiadores debemos elaborar trabajos de investigación histórica que contribuyan a afianzar nuestros modelos.

13 J. M. Santana, La historia contrataca, Barquisimeto, Fundación Buría, 2013.

14 I. Hunter, "The history of theory", Critical Inquiry, 33 (2006), pp. 78-112.

15 C. Lorenz, "History and Theory" en A. Scheneider and D. Woolf (eds.), The Oxford History of Historical Writing. Historical Writing since 1945, Oxford, Oxford University Press, 2011, pp. 14-16.

16 M. Harnecker, Los conceptos elementales del materialismo histórico, México, Siglo XXI, 1969. 
d) La construcción de estructuras explicativas. Como cualquier otra ciencia, la historia no puede existir sin sistematizar los conocimientos objetivos, sin hacer un esfuerzo por sintetizar teóricamente el material empírico, y, sin profundizar en la esencia misma de los fenómenos objeto de estudio, mediante la revelación de las tendencias internas que los rigen $^{17}$. Tratamos de buscar en el pasado esquemas y regularidades a partir de los cuales los historiadores podemos levantar propuestas. No obstante, siguiendo a E. P. Thompson consideramos que a los datos se les pueden sacar elementos que no pretendían proporcionar, aunque siempre enmarcados en un proceso histórico real que es el objetivo del conocimiento histórico. Los hechos se deben de considerar desvinculados de las formas de pensamiento pese a que los hechos y las técnicas de investigación cargan con lastres ideológicos.

e) La importancia de la metodología. El papel central en el desarrollo de la ciencia histórica le corresponde al trabajo investigador concreto. Pero una condición imprescindible para ello es elevar constantemente el nivel teórico de las pesquisas. Esto supone perfeccionar el enfoque del material que se analiza. La metodología no debe ser considerada como una circunstancia externa al trabajo del historiador, pero, al mismo tiempo, el enriquecimiento de los materiales concretos, debe servir para incrementar el nivel teórico, es decir, para fortalecer las bases metodológicas del estudio histórico. La Historia en construcción no puede hacerse sin método histórico, que no existe si no se da esa especial confrontación dialéctica entre la teoría y la "praxis" concreta del historiador. Por lo tanto, no existe tampoco la posibilidad de formulación de la teoría histórica al margen de la investigación y separada de ella, pues sólo en ese marco se concretan las instancias necesarias para que la comprensión del presente a través del análisis del pasado se convierta realmente en una actividad racional y lógicamente elaborada ${ }^{18}$.

\section{LAS NOVEDADES HISTORIOGRAFÍCAS DESDE 1989}

Desde 1945 a 1970 dominó el panorama epistémico la filosofía de la historia analítica, que estaba basada en las ideas de Hempel, y que supuso una época distinguida por amplios debates entre filósofos e historiadores bajo la dominación del llamado positivismo lógico. En los años setenta y sobre todo en los ochenta, esta situación cambia con la aparición de la llamada filosofía narrativa, con la irrupción de nombres como White, Ankersmit, Ricoeur, Rüsen y la puesta en discusión de las ideas de representación o metahistoria. Además, en esos años se fomentaron las discusiones entre los hermeneutas (Gadamer), los deconstructivistas (Derrida), la descripción densa (Geertz), el nuevo historicismo (Greenblatt) y la teoría crítica (Habermas). Los debates se centraron en que la práctica histórica y la hermenéutica no son estáticas ni objeto de un consenso generalizado. Habermas incluye los avances de la hermenéutica filosófica como un aspecto fundamental en la tarea investigadora en las ciencias sociales ${ }^{19}$, aunque no sin provocar revuelo entre los pensadores más significativos de la filosofía hermenéutica. De tal forma, Gadamer

17 P. Vilar, Iniciación al vocabulario del análisis histórico, Barcelona, Crítica, 1982, pp. 43-47.

18 E. P. Thompson, Miseria de la teoría, Barcelona, Crítica, 1981, p. 84.

19 J. Habermas, Conciencia moral y acción comunicativa, Barcelona, Península, 1991, pp. 31 y ss. Para él la hermenéutica no rompe todavía con la racionalidad interna a la historia y su continuidad, tal como la modernidad la presentaba; en U. Ferrer, "La concepción postmoderna de la historicidad", en W. J. González, Acción e Historia. El objeto de la Historia y la teoría de la acción, La Coruña, Universidad de La Coruña, 1996, p. 185. En esta obra Habermas elogia el intento de Kohlberg por desarrollar una teoría de las competencias morales en la línea piagetiana, una teoría que sería al mismo tiempo, evolutiva y universalista. En este sentido discrepamos de Habermas y creemos que lo mismo que puede concebirse una teoría de la sociedad puede también concebirse otra de la historia como ha señalado J. Aróstegui, La investigación histórica: Teoría y método, Barcelona, Crítica, 1995, p. 158. 
responde a Habermas que la hermenéutica no es asunto de la metodología, sino que es en todo caso un arte. Este autor explica su teoría en el contexto de la tradición alemana de las ciencias del espíritu, achacando a Habermas y a Apel que no se den cuenta de que la reflexión sobre la praxis no es técnica ${ }^{20}$.

Por su parte, desde los años 90 , se ha pasado a una cierta pluralidad de enfoques donde destacan la "otredad" y sus formas de representación, el pasado traumático (la memoria), el lenguaje como forma de acción performativa (J. L. Austin y John Serle), el análisis del discurso (Foucault) y los nuevos estudios sobre la historia o las humanidades digitales. Algunos historiógrafos han querido reducir todos estos cambios a una suerte de "giro lingüístico", es decir, a que la historia es discurso, y que sólo se puede entender conociendo la lengua en la que la gente piensa, habla y toma decisiones. Algunos historiadores tentados por estos presupuestos, argumentan que son las ideas y conceptos expresados en los términos característicos de una época los que explican lo que sucedió y por qué. Pero a menos que cambien los propios hechos, los cambios en las palabras utilizadas para describirlos no bastarán para modificarlos ${ }^{21}$.

Desde los años 90, por tanto, la Historia es una ciencia ubicua, es decir, que todo lo pretende abarcar y vive en constante movimiento. La etapa que estamos viviendo tiene entre otras características, los conflictos entre las diversas corrientes políticas que pugnan por el poder. Cada una de ellas se sustenta en una teoría de la historia que asiste a sus análisis y proyectos. De tal forma, asistimos en el siglo XXI a un cambio en la concepción del mundo frente al enfrentamiento del siglo XX entre las derechas y las izquierdas. Esta variación llevó en primer lugar a Fukuyama a levantar acta de defunción de la Historia, y a su secuestro ${ }^{22}$ por parte de algunos sectores del conservadurismo epistémico y, sobre todo, por parte de algunos filósofos de la posmodernidad. Actualmente, los historiadores realizamos una labor deslegitimadora para recuperar a Clío de la prisión forzosa en la que se encuentra enclaustrada por los paladines del American Way of Life como el mejor de los mundos posibles. Es necesario que una parte de la profesión se proponga recuperar la historia de los embates que en las dos últimas décadas ha estado recibiendo por parte de los neoconservadores de Estados Unidos con sus tesis sobre "el fin de la Historia", "el choque de civilizaciones" o la "brecha transatlántica". Debemos hacer mayores esfuerzos para resaltar lo que la historia crítica puede aportar a la historiografía, para defender la historia frente a aquellos que niegan su capacidad para ayudarnos a comprender el mundo.

Es así como a partir de estos años noventa nos encontramos con las siguientes novedades historiográficas:

a) Los estudios sobre el presente o la ampliación de la historia al presente, cuestión que empezó con la escuela de los Annales y el Instituto de Historia del Tiempo Presente, pero que tuvo su sustento teórico en la historia del presente de Foucault, cuando se inició la batalla del lenguaje y de la microfísica del poder. En la misma línea están las ideas constructivistas del poder del conocimiento (y su utilización por Said) o los estudios de la Cambridge School of the History of Political History (Pocock y Skinner) ${ }^{23}$. La Historia del Tiempo Presente supone el retorno de lo político, a la vez que da respuesta a la demanda social ante esas cuestiones ${ }^{24}$.

20 H. G. Gadamer, Verdad y método, vol. I, Salamanca, Sígueme, 1993, p. 646.

21 E. Hobsbawm, Guerra y paz en el siglo XXI, Madrid, Público, 2009, p. 65.

22 J. M. Santana, "La historia en el fin de una época o el secuestro de Clío", en C. Barros (ed.), Historia a Debate. Actas del I Congreso Internacional Historia a debate, T. I, Santiago de Compostela, Xunta de Galicia, 1995, pp. 249-250.

23 C. Lorenz, "History and Theory" en A. Scheneider and D. Woolf (eds.), The Oxford History of Historical Writing. Historical Writing since 1945, Oxford, Oxford University Press, 2011, pp. 26-27.

24 J. P. Rioux, "Historia del Tiempo Presente y demanda social", Cuadernos de Historia Contemporánea, 20 
La Historia del Tiempo Presente estudia la historia vivida y la presencia física del historiador en los tiempos que estudia. En 1980 se crea un seminario sobre la cuestión dirigido por F. Bedarida ${ }^{25}$ y en el diccionario de Ciencias históricas ${ }^{26}$ aparecen las voces Historia del Tiempo Presente, Historia Inmediata e Historia política. En ese momento se empieza a diferenciar entre la Historia del Tiempo Presente, la "histoire proche" y la historia inmediata ${ }^{27}$. A la vez se iniciaba la publicación de los Cahiers de Histoire du Temp Present y el Bulletin del IHTP, así como la revista Vingtiéme Siècle ${ }^{28}$. En 1989-90, a partir del Instituto de Estudios Políticos y Pluridisciplinares de América Latina (Universidad de Toulousse) surge el Grupo de Investigación de Historia Inmediata alrededor de tres ejes fundamentales: a) preocupación metodológica; b) interdisciplinaridad; c) dimensión pedagógica ${ }^{29}$. Posteriormente se intentaron mezclar todas estas sensibilidades en el sentido de que la Histoire des Temps Presentes evoluciona en un contexto histórico y la percepción inmediata de la historia ${ }^{30}$. Estas ideas se han desarrollado en España con otros nombres como "historia del presente", "historia de nuestro tiempo", "historia actual"31 o "historia inmediata". Lo mismo sucede en América Latina, donde también se denomina "historia reciente".

b) Directamente de las preocupaciones del presente están las relaciones entre la historia y la memoria o el trauma histórico. Esta línea de trabajo ha fomentado la historia y la memoria, sus conexiones y sus diferencias, así como la memoria y el individuo o la memoria colectiva ${ }^{32}$. Haciendo un poco de repaso, a fines del XIX y principios del XX se empieza a elaborar el concepto de memoria colectiva, principalmente por Halbwachs, que es el fundador de la sociología de la memoria y quien acuña el concepto. Halbwachs incide en el carácter social de la memoria, donde los recursos individuales se ubican en una "memoria colectiva" ${ }^{3}$. Halbwachs diferenciaba la historia de la memoria colectiva. Después de esto, Pierre Nora ${ }^{34}$ retomará todos estos debates continuando con esa separación entre historia y memoria bajo tres pivotes: la memoria como fuente para la historia, la memoria como objeto de estudio para los historiadores y el papel de la investigación histórica para corregir memorias equivocadas o falsas ${ }^{35}$.

(1998), pp. 71-81.

25 Ver F. Bedarida, L'Histoire et le métier d'historien en France 1945-1995, Paris, Editions de la Maison des Sciences de l'Homme, 1995.

26 A. Burguière, Dictionnaire des sciences historiques, Paris, Presses Universitaires de France, 1986.

27 Ver J. P. Rioux, "Peut-on faire une histoire du temps présent?", en A. Chauveau et P. Tétart, Questions à l'histoire des temps présents, Paris, Éd. Complexe, 1992, pp. 43-55.

28 Cuya leyenda es:" Vingtième Siècle traite de l'histoire contemporaine des années 1890 à nos jours. Son but est de fournir des clés pour mieux comprendre notre époque, en faisant le lien entre les résultats de la recherche en histoire et les questions actuelles.".

29 J. F. Soulet, L'histoire immédiate: historiographie, sources et méthodes, París, A. Colin, 2009. Previamente había publicado: J. F. Soulet, L'histoire immédiate, Paris, Presses universitaire de France, 1994.

30 A. Chauveau et P. Tétart, Questions à l'histoire des temps présents, Paris, Éd. Complexe, 1992.

31 Destaca la Asociación de Historia Actual (http://www.historia-actual.org/) y M. C. Chaput y J. PérezSerrano (eds.), La transición española. Nuevos enfoques para un viejo debate, Madrid, Biblioteca Nueva, 2015. Ver también: A. Pinilla, Ideología e información: la prensa francesa ante la muerte de Franco, Cáceres, Universidad de Extremadura, 2013.

32 G. Cubitt, History and Memory, Manchester, Manchester Universtity Press, 2007.

33 M. Halbahws, La memoria colectiva, Zaragoza, Universidad de Zaragoza, 2004 y Los marcos sociales de la memoria, Barcelona, Anthropos, 2004.

34 P. Nora (dir.), Les Lieux de Mémoire, Paris, Gallimard, 1997.

35 Ver F. Erice, Guerras de la memoria y fantasmas del pasado. Usos y abusos de la memoria colectiva, Oviedo, Eikasia, 2009, p. 78. 
En los últimos años, se ha puesto en cuestión esa diferenciación entre historia y memoria, con la irrupción de los estudios del discurso, bajo la cobertura teórica de los tres grandes giros identificados en los últimos años, el lingüístico, el hermenéutico y el subjetivo ${ }^{36}$. Por ejemplo las historias nacionales tienen una configuración fundamental para la configuración de memorias y de legitimación identitaria. Los recuerdos son continuamente elaborados por una memoria escrita en el espacio público, sometidos a modos de pensar colectivos pero influidos por paradigmas científicos ${ }^{37}$. Algunos autores, como François Dosse señalan que frente al experto historiador que privilegia la verdad y deja a la memoria la función de la fidelidad podemos preguntarnos qué valor tendrían una verdad sin fidelidad y una fidelidad sin verdad. Para articular ambas tenemos que recurrir al relato ya que la historia y la memoria son un modo de selección en el pasado, una construcción intelectual ${ }^{38}$. Nos encontramos ante una memoria histórica activa ${ }^{39}$ donde se preserva la memoria y la historia con el arbitrio de la historiografía ${ }^{40}$. No hay memorias inocentes pero tampoco hay historias objetivadas, sin presencias subjetivas (y memorias) ${ }^{41}$.

c) Estudios sobre la censura, que es un proyecto que responde a la responsabilidad del historiador y a su compromiso con la situación de persecución, censura e incluso muerte de los historiadores ${ }^{42}$. Responde a la unión de la historia con los derechos humanos. Existe una red Ilamada "Network of Concerned Historians" que "wants to provide a bridge between international human rights organizations campaigning for censored or persecuted historians (and others concerned with the past) and the global community of historians" 43 , además de otras iniciativas, como la encabezada por el professor Carlos Barros y denominada "Academia solidaria"44.

d) Los estudios postcoloniales. Como historia crítica empezaron en los años setenta y fueron promovidos por Ranajit Guha ${ }^{45}$. De ahí se pasó a los estudios del discurso donde adquieren especial importancia conceptos como la subalternidad, la marginación y la otredad. Una parte de estos estudios se integran en los Cultural Studies y otra en la configuración de los estudios sobre el discurso y la localización del poder ${ }^{46}$. La crítica del colonialismo y el nacionalismo han transformado la historiografía del sur de Asia ${ }^{47}$. Esto se ha visto reforzado por la aparición de la revista Postcolonial Studies (Taylor and Francis) en 1998, el más

36 Ver F. Erice, Guerras de la memoria y fantasmas del pasado. Usos y abusos de la memoria colectiva, pp. 55-58

37 E. Traverso, El pasado, instrucciones de uso. Historia, memoria, política, Madrid, Marcial Pons, 2007. Ver también Juan Sisinio Pérez Garzón y Eduardo Manzano Moreno, La memoria histórica, CSIC, Madrid, 2010.

38 F. Dosse, La historia: conceptos y escrituras, Buenos Aires, Nueva Visión, 2004, pp. 217-218 citado en F. Erice, Francisco, Guerras..., 2009, p. 81.

39 Ver conferencia de Carlos Barros en Montevideo en el año 2007 al respecto en www.h-debate.com

40 Ver P. Vilar, Memoria, historia e historiadores, Valencia, Universidad de Valencia, 2004.

41 Ver T. Todorov, La memoria, ¿un remedio contra el mal?, Barcelona, Arcadia, 2009.

42 A. De Baets, Censorship of Historical Thought: A World Guide 1945-2000, London, Westport Conn, 2002.

43 Ver "Network of Concerned Historians", http://www.concernedhistorians.org/content/home.html, (Consulta: 10-08-2016)

44 Ver página web: www.h-debate.com

45 R. Guha, Subaltern Studies Reader, 1986-1995, Minneapolis, University of Minnesota Press, 1993.

46 D. Chakrabarty, Provincializing Europe: Postcolonial Thought and Historical Difference, Princeton, Princeton University Press, 2000.

47 G. Prakash, "Postcolonial criticism and History: subaltern studies", en A. Scheneider and D.Woolf (eds.), The Oxford History of Historical Writing. Historical Writing since 1945, Oxford, Oxford University Press, 2011, pp. 74-91. 
reciente Postcolonial Interventions: An Interdisciplinary Journal of Postcolonial Studies o el Journal of Commonwealth and Postcolonial Studies (1993), así como la fundación de la Postcolonial Studies Association ${ }^{48}$.

e) Otra novedad derivada de los cambios posteriores a 1989 es la World History, entendida como historia transcultural. Siguiendo a Braudl o William H. McNeill49 se ha reflexionado en ella sobre los conceptos de estado y nación así como las ideas de historia atlántica o la historia de los imperios. Las revistas Journal of World History y Journal of Global History han ayudado a estudiar sobre y desde la historia regional, la historia transnacional y el eurocentrismo. Incluso se ha debatido este tipo de historia desde sensibilidades postcoloniales ${ }^{50}$. Esta historia ha dado también salida a la llamada Global Economic History ${ }^{11}$, que a la vez tiene sus propias asociaciones, como la Global Economic History Network (GEHN) ${ }^{52}$.

f) La Global History se ha convertido en una tendencia historiográfica con mayor recepción no sólo en los ámbitos de la historia contemporánea, sino también en otras épocas históricas. El despegue definitivo de este tipo de historia ha estado vinculado a la emergencia de la globalización como proceso transformador de las sociedades en los años noventa del siglo pasado. La Global history se desarrolló con el despegue de internet. De tal forma, surgió una comunidad dentro de la comunidad académica H-Net denominada "H-World", que es una red de comunicación entre los historiadores que hacen la "global history". También podemos identificar en esa misma época el nacimiento de la World History Association (WHA) y el Journal of Global History. Los enfoques eurocéntricos y la convergencia regional de muchos de los estados desde la puesta en marcha de los procesos de globalización son dos de las grandes áreas de trabajo. Autores como Bruce Mazlish, Patrick Manning y Sebastian Conrad $^{53}$ son algunos de sus mejores representantes.

g) La historia de las mujeres también ha sido una línea muy fértil en los últimos años ${ }^{54}$. Hemos pasado por la historia de la clásica historia de las mujeres surgida en los años setenta a la historia de género, donde se estudia la construcción cultural de la feminidad ${ }^{55}$. De aquí se ha pasado al postfeminismo, que desdobla la teoría feminista académica entre

48 Ver http://www.postcolonialstudiesassociation.co.uk/

49 W. H. Mcneill, "The Rise of the West after Twenty-five Years", Journal of World History, 1 (1990), pp. 1-21.

50 R. Guha, History at the Limit of World-History (Italian Academy Lectures), New York, Columbia University Press, 2002.

51 Ver K. Pomeranz, The Great Divergence: China, Europe and the Making of the Modern World, Economy, Princeton, Princeton University Press, 2000 y P. Vries, "Global Economic History: a survey" en A. Schneider and D. Woolf (eds.), The Oxford History of Historical Writing. Historical Writing since 1945, Oxford, Oxford University Press, 2011, pp. 113-135.

52 Ver http://www.lse.ac.uk/economicHistory/Research/GEHN/Home.aspx

53 P. Manning, World History: Historians Create a Global Past, Palgrave Macmillan, New York, 2003; Bruce Mazlish y Ralph Buultjens, Conceptualizing Global History, Westview Press, Boulder, 1993; S. Conrad, What Is Global History?, Princeton University Press, Princeton, 2016.

54 C. Pallares, Historia das mulleres en Galicia, Santiago de Compostela, Nigratrea, 2011 y R. M. RodríguezMagda, Mujeres en la historia del pensamiento, Barcelona, Editorial Anthropos, 1997. Para una perspectiva más panorámica, ver: E. Amico (ed.), Reader's Guide to Women's Studies, London, Taylor and Francis, 1998.

55 J. M. Bennett and R. Mazo (eds). The Oxford Handbook of Women \& Gender in Medieval Europe, Oxford, Oxford University Press, 2013; I. Blom et al. "The Past and Present of European Women's and Gender History: A Transatlantic Conversation", Journal of Women's History 25,4 (2013), pp. 288-308; S. Tubert (coord), Del sexo al género: los equívocos de un concepto, Madrid, Cátedra, 2003; S. O. Rose, What is Gender History?, Cambridge, Polity Press, 2010; K. Dierks, "Men's History, Gender History, or Cultural History?", Gender \& History, 14 (2002), pp. 147-51. 
el "gender feminism" y el "equity feminism", que conlleva la igualdad legal olvidándose del tratamiento preferente y de "víctimas" que está asociado al feminismo más convencional ${ }^{56}$. Esto le lleva a ser considerado como antifeminista ${ }^{57}$. Por último también están los Queer studies, que contienen el trabajo sobre diferentes modalidades de identidad sexual ${ }^{58}$.

h) De la historia de las mujeres surgió la historia de género, concepto sobre el que se van a construir las relaciones entre los diferentes sexos y roles. Los Gender Studies se van a situar en el centro de estas reflexiones para dar cobertura al estudio de las representaciones, las funciones, los discursos o los símbolos. El discurso seminal de esta tendencia historiográfica se debe al texto de Joan Scott Gender and the Politics of History, New York, Columbia University Press, $1988^{59}$.

i) La historia de la historia medioambiental, que es la historia de la interacción del hombre con la naturaleza, las políticas de historia medioambientales y la historia cultural e intelectual del medioambiente ${ }^{60}$. Desde la escuela de los Annales hasta los años 60 es cuando toma cuerpo este tipo de historia. Los movimientos sociales generados en los años 70 apuntalan esta historia mediante el compromiso político y generaron un diálogo entre las ciencias ambientales, la historia y otras disciplinas. En 1999 se crea la Sociedad Europea de Historia Ambiental (ESEH). En ese momento los objetivos de este tipo de historia ya habían variado. Están menos relacionados con la militancia y más orientados a concebir las mujeres y los hombres en su entorno y las relaciones entre ambos ${ }^{61}$, siempre con el cambio climático y el movimiento ecologista de fondo.

j) La antigua historia de las Mentalidades, hoy convertida en Historia Cultural ${ }^{62}$. En otra época denostada por el economicismo imperante, se nos revela como un campo de investigación extremadamente fecundo que toma a los seres humanos en sus motivaciones conscientes o no, y en las actitudes que las prolongan. Ahora tenemos la historia de la vida

56 También hay trabajos mixtos entre egohistoria e historia de género: F. Thébaud, "Entre parcours intellectuel et essai d'ego-histoire. Le poids du genre", Genre \& Histoire, 4 (2009), <http://genrehistoire.revues.org/697>, (Consulta: 10-08-2016)

57 M. K. Tulsa, "Feminism, Ethics, and History, or What Is the 'Post' in Postfeminism?", Studies in Women's Literature, vol. 21, núm. 1 (Spring 2002), pp. 29-44; R. GILL, "Postfeminist media culture. Elements of a sensibility", European Journal of Cultural Studies, 10, 2 (2007), pp. 147-166; C. Hoff Sommers, Who Stole Feminism? How Women Have Betrayed Women, London, Simon \& Schuster, 1994; P. Aronson, "Feminists or 'Postfeminists'?: Young Women's Attitudes toward Feminism and Gender Relations", Gender and Society, 17, 6 (2003), pp. 903-22; M. Lazar, "Recuperating feminism, reclaiming femininity: Hybrid postfeminist Identity in consumer advertisements", Gender and Language, 8, 2 (2014), pp. 205-224.

58 K. Floyd, The Reification of Desire: Toward a Queer Marxism, Minneapolis, University of Minnesota Press, 2009; R. Halwani, C. Quinn, and A. Wible (eds.), Queer Philosophy. Presentations of the Society for Lesbian and Gay Philosophy, 1998-2008, New York, Rodopi, 2012; R. Mcruer, Crip Theory: Cultural Signs of Queerness and Disability, New York, New York University Press, 2006.

59 J. Scott, Gender and the Politics of History, Columbia University Press, New York, 1988.

60 J. R. Mcneill, "Environmental History" en U. Rublack (ed.), A Concise Companion to History, Oxford, Oxford University Press, 2011, pp. 299-315 y J. R. McNeill and P. Engelke, The Great Acceleration: An Environmental History of the Anthropocene since 1945, Cambridge, Harvard University Press, 2016. Así como R. Chakrabarti (ed.), Situating Environmental History, New Delhi, Manohar, 2007; J. D. Hughes, An Environmental History of the World: Humankind's Changing Role in the Community of Life, Oxford, Routledge, $2001 \mathrm{y} \mathrm{M.} \mathrm{Williams,}$ Deforesting the Earth: From Prehistory to Global Crisis. An Abridgement, Chicago, University of Chicago Press, 2006.

61 Ver A. Dichdji, "La historia medioambiental: la mirada latinoamericana y Argentina", Historiografías, 12 (Julio-Diciembre de 2016), pp. 54-69.

62 Entendemos por cultura un conjunto singular de formas fenoménicas en relación a la formación social, de este modo, cultura y formación social son dos dimensiones indisolubles de la realidad social. 
privada, la historia del cuerpo y la historia de los sentimientos o de las emociones ${ }^{63}$ como puntas de lanzas de esta historia. Esta línea de trabajo se circunscribe al estudio de los procesos culturales en una perspectiva multidisciplinar, sobre todo con el surgimiento de los llamados "cultural studies" ${ }^{4}$ ponen el énfasis en el estudio entre lo cultural y la formación social y su interacción con contextos contemporáneos y textuales ${ }^{65}$.

k) La propuesta decolonial está encabezada por Walter Mignolo y su libro La idea de América Latina. La herida colonial y la opción decolonial ${ }^{66}$, que emerge de los llamados "Cultural Studies". Los tópicos que se desarrollan en esta propuesta decolonial giran alrededor de la crítica del universalismo eurocéntrico: a) una descolonización de la modernidad eurocéntrica; b) que no hay modernidad sin colonización; c) que la colonización del siglo XV preña el útero de la modernidad de colonialismo y capitalismo; d) que la modernidad es el dominio del mundo desde Occidente; e) que el resultado es un maridaje entre capitalismo, colonización y modernidad ${ }^{67}$.

Mignolo se sustenta en otros autores importantes que habían manejado estas ideas de la relación entre el mundo moderno/colonial, como Enrique Dussel, Anibal Quijano, Ramón Grosfoguel o Ezequiel Martínez Estrada. Esto ha dado lugar a nuevas perspectivas. Por ejemplo, el profesor Canaparo trabaja con lo que se denomina la "localización del conocimiento", que defiende que el conocimiento es una evolución cultural, una perspectiva historiográfica y una difusión pública de conceptos en su concepción y diseño ${ }^{68}$. Se trata de no separar epistemología y territorio (geoepistemología) ${ }^{69}$ y también de precisar la conexión entre pensar geográficamente sobre los límites de un territorio y observar qué tipo de conocimiento se da dentro de él ${ }^{70}$.

I) La historia digital, que se construye desde un profundo análisis práctico-teórico del presente y del pasado, teniendo como eje fundamental la relación entre la historia e internet ${ }^{71}$, aunque el pasado se vuelve digital en la medida que los documentos se digitalizan, en lo que Anaclet Pons denomina "el más grande trastorno que ha vivido la corporación académica

63 W. Reddy, The Navigation of Feeling: A Framework for the History of Emotions, Cambridge University Press, Cambridge, 2001 y B. H. Rosenwein, Emotional Communities in the Early Middle Ages, Cornell University Press, Ithaca and London, 2006.

64 Los "Cultural Studies" surgen en los años 50 con R. Hoggart's The Uses of literacy, London, Transaction Publishers, 1957; R. Wiliams, Culture and Society, Columbia University Press, New York, 1958 y E. P. Thompson, The Making of the English Working Class, Phanteon Books, New York, 1963. Para una perspectiva general, ver J. Munns and G. Rajan, A Cultural Studies Reader. History, Theory, Practice, Longman, London, 1995.

65 Ver T. Serequeberhan, "The Critique of Eurocentrism" en E. Eze (ed.), Postcolonial African Philosophy, Oxford, Blackwell, 1999.

66 W. D. Mignolo, La idea de América Latina. La herida colonial y la opción decolonial, Barcelona, Gedisa, 2007.

67 Sobre todo en The Idea of Latin America, Oxford, Blackwell Publishing, 2005, y The Darker Side of the Renaissance Literacy, Territoriality and Colonization (1995); Local Histories/Global Designs. Coloniality; o Subaltern Knowledges and Border Thinking, Princeton, Princeton University Press, 2000.

68 C. Canaparo, Geo-epistomology: Latin America and the location of knowledge, London, Peter Lang, 2009, p. 22. Ezequiel Martínez Estrada y Alfonso Reyes han sido dos autores que se han ocupado de esto.

69 Previo a C. Canaparo ver E. Dussel, América Latina dependencia y liberación, Buenos Aires, García Cambeiro, 1973.

70 C. Canaparo, Geo-epistomology: Latin America and the location of knowledge, pp. 23-26.

71 Ver D. Seefeldt and W. G. Thomas, "What Is Digital History?", Perspectives on History, May 2009 https:// www.historians.org/publications-and-directories/perspectives-on-history/may-2009/intersections-history-andnew-media/what-is-digital-history (Consulta: 14-03-2016) 
en los últimos tiempos"72. La historia digital cambia la escritura de la historia en las nuevas formas de producción, de comunicación y de ejercicio diario de la profesión de historiador. Como consecuencia de esto, podemos identificar las siguientes líneas de trabajo: a) reconocer y analizar las mutaciones provocadas por la historia digital y las humanidades digitales; b) explorar en profundidad la influencia de las nuevas tecnologías para el trabajo académico (docencia e investigación); c) el impacto de las nuevas herramientas digitales en la escritura de la historia (nuevas perspectivas metodológicas y teóricas). La novedad y la falta de teorización sobre los cambios, crea, como hemos dicho, una indefinición epistémica que lleva a las Humanidades Digitales a ser para unos un campo de trabajo heterodoxo ${ }^{73}$ y para otros un ámbito de trabajo definido en relación a sus practicantes ${ }^{74}$. En este entorno digital, han surgido el problema de la métrica de las investigaciones (citas y factores de impacto) y las evaluaciones (pares ciegos). Frente a esto han surgido iniciativas en contra, como la Declaración de San Francisco, que defiende que no se utilicen las métricas de las revistas para sustituir a los artículos individuales ${ }^{75}$.

m) Historia y literatura. Las relaciones entre historia, autoría, escritura, literatura y política ${ }^{76}$ tanto en la historia contemporánea como en la historia medieval ${ }^{77}$. De tal forma tenemos un nuevo abordaje en el estudio de los textos. Novelas históricas o crónicas medievales son analizadas y estudiadas como producto de un discurso histórico e historiográfico y no como una mera representación literaria de un autor. Esto ha dado lugar a nuevas formas de historia como el llamado "nuevo medievalismo"78.

n) La egohistoria, que es la reflexión sobre la propia historia y trayectoria intelectual de los historiadores. Fue iniciada por Pierre Nora $^{79}$ en los años ochenta, pero ha tenido un gran impulso en los últimos años. No es una autobiografía literaria; ni es el resultado de confesiones íntimas ni de intentos de psicoanálisis. Se trata de escribir la propia historia del historiador como si fuera la de otro ${ }^{80}$.

72 A. Pons, El desorden digital. Guía para historiadores y humanistas, Madrid, Siglo XXI, 2013, p. 27.

73 Ver "Digital Humanities Manifiesto 2.0", ucla.edu, 29 mayo de 2009, http://manifesto.humanities.ucla. edu/2009/05/29/the-digital-humanities-manifesto-20/, (Consulta: 22-06-2016) y "Manifieste des Digital Humanities", hypotheses.org, 26 de marzo de 2016, http://tcp.hypotheses.org/318, (Consulta: 22-06-2016).

74 Ver S. Schreibman, R Siemens and J. Unsworth (eds.), Companion to Digital Humanities, Oxford, Blackwell, 2004.

75 La Declaración de San Francisco surgió en la Reunión Anual de la Sociedad Americana de Biología Celular (BCSV) que se celebró San Francisco, el 16 de diciembre de 2012. El grupo desarrolló una serie de recomendaciones, conocidas como la Declaración de San Francisco de Evaluación de la Investigación. Ver "Declaración de San Francisco", http://blogs.ujaen.es/cienciabuja/wp-content/uploads/2013/10/dora. pdf, (Consulta: 10-05-2016]. Esta declaración de San Francisco se ha visto reforzada posteriormente por el Manifiesto de Leiden: http://www.leidenmanifesto.org/

76 J. Canal, La historia es un árbol de historias. Historiografía, política, literatura, Universidad de Zaragoza, Zaragoza, 2014.

77 D. M. Deliyannis (ed.), Historiography in the Middle Ages, Leiden 2003, R. Mckitterick, Perceptions of the Past in the Early Middle Ages, Indiana, University of Notre Dame Press, 2006; R. Flechner y M. Ni Mhaonaigh (eds.), The Introduction of Christianity into the Early Medieval Insular World. Converting the Isles I, Turnhout, Brepols, 2016; I. H. Garipzanov (ed.), Historical Narratives and Christian Identity on a European Periphery. Early History Writing in Northern, East-Central, and Eastern Europe (c.1070-1200), Turnhout, Brepols, 2011; C. Høgel and E. Bartoli (eds.), Medieval Letters. Between Fiction and Document, Turnhout, Brepols, 2015.

78 J. Aurell, La historiografía medieval: entre la historia y la literatura, Universidad de Valencia, Valencia, 2016.

79 Aunque después ha seguido reflexionando sobre ello: P. Nora, "L'ego-histoire est-elle possible?", Historein, vol. 3 (2001), pp. 19-26

80 J. Aurell and F. Crosas (eds.), Rewriting the Middle Ages in the Twentieth Century, Turnhout, Brepols, 2005; 
o) Historia y enseñanza de la historia, en la que destacan los estudios de la historia como disciplina formativa y las reflexiones sobre la enseñanza de la historia desde la perspectiva del historiador y no desde la matriz pedagógica. El sentido de la investigación en el aula ofrece también nuevas perspectivas para la divulgación y la investigación históricas ${ }^{81}$.

\section{ENTRE LA METODOLOGÍA Y LA HISTORIOGRAFÍA: ELEMENTOS EPISTÉ- MICOS A DEBATE.}

Después de desarrollar algunos aspectos historiográficos y metodológicos que hemos acotado después de 1989, nos proponemos reflexionar sobre los aspectos epistémicos que subyacen de ellos. De tal forma tenemos los siguientes elementos:

a) Las categorizaciones conceptuales. Ha habido una huida foucaultiana de los "ismos" para llegar a una avalancha lyotardiana de los "pos". Así, gran parte de aquella generación de historiadores formados en las interpretaciones socio-económicas y materialistas, se autodenominan posmodernos, posmarxistas, postestructuralistas, poscoloniales 0 pospolíticos. Algo similar ha ocurrido con los "neo". Se trata de dos prefijos que hacen alusión a la temporalidad. En realidad, enmascaran una postura muy ideológica, que consiste en decir que se sitúan más allá del fin de las ideologías, obvia falacia, que trata de esconder las contradicciones de clase y enmascararlas en el plano cultural ${ }^{82}$. Como dijo Pierre Bourdieu los conceptos tienen una historia y, estos prefijos nos son asépticos, sino que designan.

b) Las civilizaciones como bloques compactos no existen, en el seno de cada civilización hay realidades, experiencias muy distintas. El Norte ha penetrado en el Sur, y el Sur es parte del Norte geopolítico. Hay muchas interconexiones entre las distintas culturas. La tesis del choque de civilizaciones es un truco como el de los efectos especiales de una película, útil para reforzar el orgullo defensivo más que para dar una interpretación crítica de la desconcertante interdependencia de nuestra época. Desde los países pobres no hay un verdadero rechazo a las culturas del mundo occidental sino que se oponen a la imposición del modelo americano como única forma de vida ${ }^{83}$. La recuperación de la historia resulta necesaria para manejar las claves explicativas que nos guíen hacia el conocimiento y la proyección de futuros acontecimientos. Solo la historia, y especialmente una historia que combine adecuadamente los elementos objetivos con las subjetividades, puede servir para analizar teorías explicativas del orden mundial basadas en la historia, como las del fin de la historia y el choque de civilizaciones.

De esta forma, determinados aspectos de la historia pasan a un primer plano, un ejemplo de ello es el interés por las Cruzadas y otros temas de enfrentamientos entre el

G. Duby, Mes Ego-histoires, Paris, Gallimard, 2015; J. D. Popkin, "Ego-Histoire and Beyond: Contemporary French Historian-Autobiographers", French Historical Studies, vol. 19, núm. 4 (1996), pp. 1139-1167. Y también A. Geppert and L. Passerini (eds), European Ego-Histoires: Historiography and the Self, 19702000, Athens, Nefeli, 2001 y J. Aurell "Del logocentrismo a la textualidad: la autobiografía académica como intervención historiográfica", Edad Media: revista de historia, 9 (2008), pp. 193-222; J. Aurell, "Making History by Contextualizing Oneself: Autobiography as Historiographical Intervention", History and Theory, vol. 54 (2015), pp. 233-268; J. Aurell, Theoretical Perspectives on Historians' Autobiographies. From Documentation to Intervention, New York, Routledge, 2016; J. Aurell (ed.), La historia de España en primera persona. Autobiografías de historiadores hispanistas, Barcelona, Editorial Base, 2012.

81 E. Moradiellos, Clío en las aulas. Ensayo sobre educación e historia, Badajoz, Diputación de Badajoz, 2012; J. Prats y J. Santacana, "Nous paradigmes en l'ensenyament de la historia", Educació i història: Revista d'història de l'educació, 26 (2015), pp. 19-39.

82 Ha sido analizada y coincidente esta postura en M. Hardt y A. Negri, Empire. Cambridge, Harvard University Press, 2000; S. Žizek, En defensa de la intolerancia. Madrid, Sequitur, 2007.

83 N. Klein, No logos. El poder de las marcas, Barcelona, Paidós, 2001. 
mundo occidental y musulmán. Un ejemplo sintomático es el ensayo-novela de divulgación del historiador británico Anthony Padgen, profesor de historia en la Universidad de California, que hace un recorrido por la historia universal y concluye que a lo largo de toda la historia, los países de Occidente y de Oriente Próximo han estado avocados a una difícil coexistencia ${ }^{84}$.

c) El tiempo y la relación entre pasado, presente y futuro. Es importante tener en cuenta la relación conflictiva entre pasado-presente-futuro. La historia se vive hacia delante y se comprende hacia atrás. Walter Benjamín decía que para encontrar sentido a un momento debemos "pensar el presente desde un punto de vista histórico". Ya en 1948 George Orwell había escrito que "quien controla el pasado controla el futuro y quien controla el presente, controla el pasado"85. El presente es fruto del pasado y sin este no se puede entender, no existiría. En definitiva, el pasado es también presente y futuro. La historia es un diálogo sin fin entre presente y pasado. El historiador ha de ser un sujeto activo en su profesión. En ella, el pasado y la historia no son sus armas, que puede utilizar a su antojo, sino su fuente de inspiración y método de análisis. Ha de contribuir al progreso, al bienestar de los demás seres humanos y a la solución de los problemas en que nos miramos; ha de ser útil.

Una de las variables más importantes con que funcionamos los historiadores es el tiempo. En la medida que hemos dicho que la función de la historia es conocer el pasado para entender el presente y proyectar el futuro. Si este deja de existir, por la crisis de la política y de los proyectos a largo plazo, el pasado y la historia dejan de interesar. Todo esto ha conducido a un presentismo; ahora no existe el futuro, sólo interesa el presente, y hay un abandono del pasado. Es lo que Michel Maffesoli ha calificado como el instante eterno ${ }^{86}$ que se manifiesta en que la historia inmediata aparece como la única temporalidad digna de ser estudiada, lo que es un nuevo embate contra la historia crítica, cuyos principales pilares son la materialidad, la dialéctica, pero también la historicidad. Incluso nuestro lenguaje ha ido evolucionando, cada vez utilizamos menos el tiempo verbal futuro y empleamos el presente para referirnos a un tiempo que no ha llegado.

En este siglo XXI la desilusión política e incredulidad en el cambio social hace creer que el presente es inmutable, por tanto ¿para qué estudiar el pasado? Se impone la salida individual (es el triunfo del neoliberalismo) o del discurso (postmodernismo), frente a la impaciencia teleológica que estaba dominando la historiografía de las pasadas décadas. En los últimos años hemos dedicado grandes esfuerzos a la historia del presente, pero no debemos caer en la tentación de hacer una historia profética, y hay que reconocer la imposibilidad de predecir el futuro. Y, por otro lado, huir también de la actitud posmoderna de negación de cualquier futuro. Al mismo tiempo, hay una predilección por el corto plazo, frente a la longue durée defendida por Braudel, (también llamado tiempo geográfico), que correspondía a las casi inmutables relaciones del hombre con el medio geográfico, dando lugar a una suerte de geohistoria y a una revitalización del interés por la geografía. Aquí percibimos un nuevo y original determinismo histórico, que es precisamente el determinismo de las estructuras de la larga duración, que le ha permitido hablar de esa "telehistoria" de las coordenadas profundas, propias del tiempo largo ${ }^{87}$. Con este concepto Braudel pretendía combatir la práctica habitual de los historiadores que concentraban sus energías en el registro de acontecimientos de corta duración. La posmodernidad es lo contrario a esa larga duración, el tiempo se contrae, como afirman Guldi y Armitage parafraseando el

84 A. Padgen, Mundos en guerra. 2500 años de conflicto entre Oriente y Occidente, Barcelona, RBA, 2011.

85 G. Orwell, 1984, Barcelona, Destino, 1952.

86 M. Maffesoli, L'instant éternel. Le retour du tragique dans les sociétés postmodernes. París, Denoël, 2000.

87 C. A. Aguirre, Braudel y las ciencias humanas, Barcelona, Montesinos, 1996, p. 43. 
inicio del Manifiesto Comunista "un fantasma recorre nuestra época: el fantasma del corto plazo", lo que beneficia al discurso sobre el presunto triunfo del capitalismo. Estos autores defienden la necesidad de devolver a la historia su misión de ciencia social crítica y fusionar el análisis micro y macro ${ }^{88}$.

d) El espacio. La otra variable fundamental para la historia, el espacio, también ha cambiado. Pasamos de la regionalización, la localización y los discursos sobre las nacionalidades a un territorio más amplio e indefinido, que abarca civilizaciones. Se presupone que todos los occidentales estamos en el mismo espacio, sobre todo, en los países ricos.

e). El sujeto (individual y colectivo). En la historiografía del siglo XXI cobra especial importancia el sujeto. A él se le asigna una conciencia y una capacidad teórica y práctica, frente a la pasividad de otras concepciones como la soviética (en favor del partido). Con ello, nos apartamos de la ortodoxia, negándonos a sancionar la concepción "materialista" del conocimiento como "reflejo" de un mundo exterior radicalmente separado de la inteligencia humana. Se trata de incorporar en la historiografía los elementos de praxis y de totalidad, integrando la dimensión activa o "subjetiva". Es la exaltación del elemento subjetivo de la historia (o, lo que es igual, de la consciencia transformadora).

Los seres humanos al hacer la historia, también pueden cambiarla, pero en medio de unas condiciones objetivas dadas, con lo que se hace preciso conciliar lo subjetivo (las personas) y lo objetivo (las condiciones dadas). Las fuerzas materiales y culturales y las relaciones de producción son inseparables como actividades de hombres y mujeres que construyen su propia historia, pero no en el vacío; no afuera de la vida material ni lejos de su pasado histórico. Hobsbawm nos alerta acerca del peligro de la negativa de algunos a admitir que existe una realidad objetiva y no construida por el observador; o de sostener que somos incapaces de superar los límites del lenguaje (es decir, de los conceptos). El gran peligro político que amenaza a la historiografía actual es el antiuniversalismo: "mi verdad es tan válida como la tuya, independientemente de los hechos". Por eso debemos mantener un combate por una investigación racional en la historia contra aquellos que la deforman con fines políticos y contra relativistas y posmodernos (incluso algunos que se consideran de izquierdas) que se niegan a admitir que la historia ofrezca esa posibilidad de racionalidad $^{89}$. La verdad es pues inseparable de un procedimiento que la establece, lo cual hace que Foucault compare la "investigación inquisitorial" que trata en Vigilar y Castigar con el "examen disciplinario" modelo de las Ciencias Humanas.

f) La objetividad. Hay una apuesta decidida por hacer historia con objetividad, pero muchas veces, historiadores y científicos sociales en general confunden objetividad con neutralidad. La neutralidad es imposible de conseguir, porque cualquier afirmación científica tiene consecuencias políticas y, por ello, beneficia a un grupo de intereses en perjuicio de otros; por eso, hay que aproximarse lo más posible a la objetividad, como recomienda Moore: “... para todos los estudiosos de la sociedad humana, la simpatía por las víctimas del proceso histórico y el escepticismo respecto a las demandas de los triunfadores proporcionan salvaguardas esenciales para no ser engañados por la mitología dominante. Un estudioso que trata de ser objetivo necesita esos sentimientos como parte de su bagaje ordinario" 90 . Nuestra historiografía se tiene que mantener enraizada en una realidad objetiva que son los problemas del pasado, lo que nos obliga a investigar para comprender cómo y por qué

88 J. Guldi y D. Armitage, Manifiesto por la historia. Barcelona, Alianza, 2016.

89 E. Hobsbawm, "El desafío de..."

90 B. Moore, Los orígenes sociales de la dictadura y de la democracia, Barcelona, Península, 1973, p. 523. 
esos problemas son formulados de la manera en que lo son en tradiciones históricas y en medios socio-culturales diferentes.

Muchas veces se exalta la "neutralidad científica", la falsa imparcialidad, el estatus "desapasionado" de los historiadores como si fuéramos hijos de ninguna parte y de ningún tiempo. Pensamos que de esta forma habremos perdido la riqueza más grande que poseemos como portadores de una serie de conocimientos que se han extraído de una realidad que no sólo a nosotros pertenece. Habremos perdido entonces la función social de la historia, su parte esencial y trascendente. Además, en esa toma de postura debemos estar siempre sensibles a los cambios (las transformaciones en el tiempo, el objeto de la historia) convencidos de que la dialéctica está en todos los episodios de la vida humana. En palabras de Samir Amín: “... la calidad de las reflexiones de los que quieren cambiar la sociedad es necesariamente mejor que la de los que quieren inmovilizarla. La razón de esto es que la sociedad cambia. Aquellos que quieren detener su movimiento se ven así pues obligados a negar la evidencia..." ${ }^{1}$. Tenemos el compromiso de defender una conjunción de los aspectos positivos de la historiografía del siglo XX para confluir en un paradigma común.

\section{CONCLUSIONES}

Dicho todo esto, pensamos que desde 1989 existen cinco ejes sobre los que pivotan las diferentes tendencias historiográficas actuales:

a) La historia crítica. La dimensión crítica de la historia filosófica de las ciencias no es en ningún caso una crítica de la ciencia ${ }^{92}$, sino que, por el contrario, es una crítica de lo negativo de la razón. El proyecto de los historiadores críticos es el de invocar los poderes del pasado histórico (perspectiva, crítica, conciencia, memoria e imaginación), que es al mismo tiempo destructivo y constructivo. Compartimos plenamente la visión de Harvey Kaye que postula que frente a los historiadores como creadores del consenso, está la visión de los historiadores como críticos sociales, que trabajan los poderes del pasado para abarcar y comprender el presente con el objetivo de contribuir a delinear nuevas direcciones en el futuro ${ }^{93}$.

El historiador hará esto intentando responder a las leyes de verificación que rigen la historia en sí, es decir, no reduciéndose a lo que ocurrió, al proceso o a las transformaciones. Uno de los objetivos que se plantea es el de mostrar que muchas de las cosas que forman parte de su paisaje y que la gente piensa que son universales, no son sino el resultado de algunos cambios históricos muy precisos. Todos sus análisis van en contra de la idea de necesidades universales en la existencia humana. El historiador muestra, así, la arbitrariedad de las instituciones, cuál es el espacio de libertad que todavía podemos disfrutar, y qué cambios pueden todavía realizarse ${ }^{94}$. Toda historia es arqueológica por naturaleza y no por elección. Explicar y hacer explícita la historia consiste en percibirla primero en su conjunto, en relacionar los supuestos objetos naturales con las prácticas de fecha concreta y rara que los objetivan y en explicar esas prácticas, no a partir de un motor único, sino desde todas las

91 S. Amín, Clases y naciones en el materialismo histórico. Un estudio sistemático sobre el papel de las naciones y las clases en el desarrollo desigual de las sociedades, Barcelona, El Viejo Topo, 1979, p. 7.

92 R. Machado, "Arqueología y epistemología", en Michel Foucault, filósofo, Barcelona, Gedisa, 1990, p. 15.

93 H. J. Kaye, La educación del deseo. Los marxistas y la escritura de la historia, Madrid, Talasa, 2007, pp. 231-234.

94 M. Foucault, Tecnologías del yo, Barcelona, Paidós, 1990. p. 144. Foucault sugiere que para poder estudiar las discontinuidades históricas tenemos que 'individualizar' los discursos, es decir, hemos de tener claro el sistema lingüístico al que pertenecen y la identidad del sujeto que los desarrolla. 
prácticas próximas en las que se asientan ${ }^{95}$. De este modo, la historia tendría una función deslegitimadora. Aquí radica la importancia de contextualizar la historia del pensamiento en una historia de estructuras sociales porque el pensamiento también es social.

b) La diversidad de la historia. No todas las historias son iguales. Podemos y debemos discriminar en función de las fuentes utilizadas y las metodologías para su tratamiento, que estarán condicionadas por las teorías, que unas son más coherentes que otras. Quizás no podamos conocer la verdad objetiva, pero los hechos del pasado sucedieron de una forma determinada y atendiendo a diversas causas, y unas historias bien reconstruidas se aproximan más que otras a lo ocurrido en el pasado. Estamos convencidos que Pierre Vilar tenía razón cuando decía que "la historia sirve para no hacerse ilusiones, y sin embargo conservar la esperanza". Los historiadores no tenemos las respuestas a las incógnitas del futuro, pero tenemos las esperanzas en otro mundo. En este sentido hay que considerar lo que puede aportarnos, temática y metodológicamente, la antropología y la psicología, o sea, todo lo relativo al sujeto humano. La historia que plasma el desarrollo psíquico es precisamente la historia del desarrollo de la sociedad humana, con todas sus formas concretas de interacción ${ }^{96}$. O sea, antropología histórica, nueva historia cultural y microhistoria son líneas de investigación que tienen en común el enfoque de la historia desde el sujeto, superando el determinismo. La emergencia de la subjetividad humana como tema de investigación histórica conlleva algunos retornos temáticos con la reafirmación de la historia subjetiva, conectada en torno a la antropología simbólica.

c) La heterodoxia. Es necesario hacer una reivindicación de la heterodoxia de cualquier sistema cerrado y acabado de interpretación, y defender el derecho a disentir de aquellos que propugnan unos catecismos a los que hay que ceñirse y que de manera mecanicista tienen todas las respuestas a cualquier pregunta posible hacia el pasado y hacia el futuro. Así, la historia de la humanidad sería una máquina perfecta donde cada consecuencia es un producto de una causa, y donde podríamos escribir cuándo, cómo y dónde se encuentra el final de esta historia interminable. Por otro lado, también podríamos levantar banderas de heterodoxia frente a quienes intencionalmente elaboran teorías que proclaman el triunfo incuestionable de las actuales teorías económicas neoliberales (los fenómenos económicos son considerados neutros y sus efectos ambivalentes, estamos ante la extensión de una ideología de la resignación, denominada pensamiento único).

d) El historiador crítico. Ante todas estas cuestiones, ¿qué hace un historiador crítico en una sociedad como esta? No basta con anhelar porque no se consigue nunca lo posible, si no se intenta lo imposible una y otra vez. Debemos seguir siendo realistas y pedir lo imposible. Esperar que un constructo político llegue a realizarse algún día por remoto que sea, es un dulce sueño, aproximarse constantemente a ese horizonte utópico no es sólo algo imaginable sino que, como afirma Kant, en cuanto puede compatibilizarse con la ley moral constituye un deber. Ante los mensajes presentistas e inmovilistas que defienden los mass media debemos trasmitir unas aspiraciones de cambio hacia mejor, atribuimos a las cosas una historia porque cambian o son capaces de cambiar. Las cosas tienen Historia y tienen tiempo, sin que importe el orden de prelación en que le atribuyamos una u otro ${ }^{97}$. En definitiva, sigue estando vigente el pensamiento gramsciano de ser realistas y pedir lo imposible. Hay que apostar por la solidaridad y no sólo con el prójimo-próximo, sino con aquellos que aún no han nacido y con el Tercer Mundo. Creemos que Latinoamérica, África

95 P. Veyne, ¿Cómo se escribe la historia?, Madrid, Fragua, 1972 p. 237.

96 L. Vigotsky, Pensamiento y Lenguaje, Madrid, Paidós, 1978, p. 3.

97 J. Arostegui, "La historia como atribución (Sobre el significado del tiempo histórico)", en C. Barros (ed.), Historia a Debate, t. III, La Coruña, Xunta de Galicia, 1995, p. 49. 
y Asia siguen firmemente preocupados por el cambio y el triunfo de una sociedad perfecta les suena onírica. Como apunta Hill los habitantes del Tercer Mundo deben estar poco seguros de que la Historia ha sido superada ${ }^{98}$.

e) La conexión entre teoría, investigación y docencia. Consideramos preciso seguir manteniendo una postura crítica contra cualquier dogma, especialmente los que difunde el poder por medio de sus múltiples aparatos de reproducción ideológica. En este sentido, resulta primordial un compromiso conducente a unificar los planteamientos teóricos filosóficos con los trabajos empíricos de investigación que abordamos cotidianamente, evitando la tan frecuente desligazón entre teoría y praxis. Una vez aunados ambos campos lo coherente es llevarlo a la docencia, hay que hacer un esfuerzo por llevar a las aulas nuestras desconfianzas en los paladines del fin de la Historia que tratan de perpetuar unas relaciones sociales de producción determinadas. Es decir, unificar teoría, investigación y docencia.

\section{BIBLIOGRAFÍA}

Aguirre, C. A., Braudel y las ciencias humanas, Barcelona, Montesinos, 1996.

Amín, S., Clases y naciones en el materialismo histórico. Un estudio sistemático sobre el papel de las naciones y las clases en el desarrollo desigual de las sociedades, Barcelona, El Viejo Topo, 1979.

Anderson, P., Los fines de la historia, Anagrama, Barcelona, 1996.

Aróstegui, J., "La historia como atribución (Sobre el significado del tiempo histórico)", en Barros, C. (ed.), Historia a Debate, t. III, La Coruña, Xunta de Galicia, 1995.

- La investigación histórica: Teoría y método, Barcelona, Crítica, 1995.

Aurell, J., "Making History by Contextualizing Oneself: Autobiography as Historiographical Intervention", History and Theory, vol. 54, 2015, pp. 233-268.

- La historiografía medieval: entre la historia y la literatura, Universidad de Valencia, valencia, 2016.

- Theoretical Perspectives on Historians' Autobiographies. From Documentation to Intervention, New York, Routledge, 2016.

Bedarida, F., L'Histoire et le métier d'historien en France 1945-1995, Paris, Editions de la Maison des Sciences de l'Homme, 1995.

Bell, D., "Choque de civilizaciones", El País, sábado 6 de agosto de 1994, pp. 9-10.

Bello, W., Desglobalización. Ideas para una nueva economía mundial, Barcelona, Icaria, 2004.

Bennett, J. M. y Mazo, R. (eds.). The Oxford Handbook of Women \& Gender in Medieval Europe, Oxford, Oxford University Press, 2013.

Burguière, A., Dictionnaire des sciences historiques, Paris, Presses Universitaires de France, 1986.

Canal, J., La historia es un árbol de historias. Historiografía, política, literatura, Universidad de Zaragoza, Zaragoza, 2014.

Canaparo, C., Geo-epistomology: Latin America and the location of knowledge, London, Peter Lang, 2009.

Chakrabarty, D., Provincializing Europe: Postcolonial Thought and Historical Difference, Princeton, Princeton University Press, 2000.

Chaput, M. C. y Pérez-Serrano, J. (eds.), La transición española. Nuevos enfoques para un

98 C. Hill, “¿Unas exequias prematuras?”, en A. Ryan, A propósito del fin de la historia, Valencia, Edicions Alfons el Magnànim, 1994, p. 22. 
viejo debate, Madrid, Biblioteca Nueva, 2015.

Chauveau, A. y Tétart, P., Questions à l'histoire des temps présents, Paris, Éd. Complexe, 1992.

Clark, T. J., "Para una izquierda sin futuro", New Left Review, 74, mayo-junio de 2012, pp. 57-67.

Conrad, S., What Is Global History?, Princeton University Press, Princeton, 2016.

Cubitt, G., History and Memory, Manchester, Manchester University Press, 2007.

De Baets, A., Censorship of Historical Thought: A World Guide 1945-2000, London, Westport Conn, 2002.

Dichdji, A., "La historia medioambiental: la mirada latinoamericana y Argentina", Historiografías, 12, Julio-Diciembre, 2016, pp. 54-69.

Digital Humanities Manifiesto 2.0, ucla.edu, 29 mayo de 2009, http://manifesto.humanities. ucla.edu/2009/05/29/the-digital-humanities-manifesto-20/, (Consulta: 22-06-2016)

Dosse, F., La historia: conceptos y escrituras, Buenos Aires, Nueva Visión, 2004.

Dubert, I., "A crise historiográfica como ideoloxía”, en Barros, C. (ed.), Historia a debate:

Galicia, Santiago de Compostela, Historia a Debate, 1995.

Dussel, E., América Latina dependencia y liberación, Buenos Aires, García Cambeiro, 1973.

Elias, N., El proceso de civilización. Investigaciones sociogenéticas y psicogenéticas, Madrid, Fondo de Cultura Económica, 1993.

Erice, F., Guerras de la memoria y fantasmas del pasado. Usos y abusos de la memoria colectiva, Oviedo, Eikasia, 2009.

Ferrer, U., "La concepción postmoderna de la historicidad", en González, W. J., Acción e Historia. El objeto de la Historia y la teoría de la acción, La Coruña, Universidad de La Coruña, 1996.

Fontana, J., La historia después del fin de la historia. Reflexiones acerca de la situación actual de la ciencia histórica, Crítica, Barcelona, 1992.

Fukuyama, F., El fin de la Historia y el último hombre, Planeta, Barcelona, 1992.

Gadamer, H. G., Verdad y método, vol. I, Salamanca, Sígueme, 1993.

Goberna, J., Civilización. Historia de una idea, Santiago de Compostela, Universidad de Santiago de Compostela, 1999.

Guha, R., Subaltern Studies Reader, 1986-1995, Minneapolis, University of Minnesota Press, 1993.

Guldi, J. y Armitage, D., Manifiesto por la historia. Barcelona, Alianza, 2016.

Habermas, J., Conciencia moral y acción comunicativa, Barcelona, Península, 1991.

Halbahws, M., La memoria colectiva, Zaragoza, Universidad de Zaragoza, 2004

- Los marcos sociales de la memoria, Barcelona, Anthropos, 2004.

Hardt, M. y Negri, A., Empire. Cambridge, Harvard University Press, 2000.

Hartog, F., Los regímenes de historicidad. Presentismo yexperiencias del tiempo, Universidad Iberoamericana, México, 2007.

Hill, C., “¿Unas exequias prematuras?”, en Ryan, A., A propósito del fin de la historia, Valencia, Edicions Alfons el Magnànim, 1994.

Hobsbawm, E., Guerra y paz en el siglo XXI, Madrid, Público, 2009.

Kaye, H. J., La educación del deseo. Los marxistas y la escritura de la historia, Madrid, Talasa, 2007.

Kiernan, V. G., "Marxismo y revolución" en A propósito del fin de la historia, Valencia, Edicions Alfons el Magnànim, 1994.

Lorenz, C., "History and Theory" en Scheneider, A. y Woolf, D. (eds.), The Oxford History of 
Historical Writing. Historical Writing since 1945, Oxford, Oxford University Press, 2011. Machado, R., "Arqueología y epistemología”, en Michel Foucault, filósofo, Barcelona, Gedisa, 1990.

Maffesoli, M., L'instant éternel. Le retour du tragique dans les sociétés postmodernes, París, Denoël, 2000.

Manifieste des Digital Humanities, hypotheses.org, 26 de marzo de 2016, http://tcp. hypotheses.org/318 (Consulta: 22-06-2016)

Manning, P., World History: Historians Create a Global Past, Palgrave Macmillan, New York, 2003.

Mazlish, B. y Buultjens R., Conceptualizing Global History, Westview Press, Boulder, 1993. Mckitterick, R., Perceptions of the Past in the Early Middle Ages, Indiana, University of Notre Dame Press, 2006.

Mcneill, J. R., "Environmental History" en Rublack, U. (ed.), A Concise Companion to History, Oxford, Oxford University Press, 2011, pp. 299-315

McNeill, W. H., "The Rise of the West after Twenty-five Years", Journal of World History, 1, 1990, pp. 1-21.

Mignolo, W. D., La idea de América Latina. La herida colonial y la opción decolonial, Barcelona, Gedisa, 2007.

Moore, B., Los orígenes sociales de la dictadura y de la democracia, Barcelona, Península, 1973.

Moradiellos, E., Clío en las aulas. Ensayo sobre educación e historia, Badajoz, Diputación de Badajoz, 2012.

Nora, P., (dir.), Les Lieux de Mémoire, Paris, Gallimard, 1997.

— "L'ego-histoire est-elle possible?", Historein, vol. 3 (2001), pp. 19-26

Pallares, C., Historia das mulleres en Galicia, Santiago de Compostela, Nigratrea, 2011

Pastor, J., Qué son los movimientos antiglobalización, Barcelona, RBA, 2002.

Pérez Garzón, J. S. y Manzano Moreno, E., La memoria histórica, CSIC, Madrid, 2010.

Pomeranz, K., The Great Divergence: China, Europe and the Making of the Modern World, Economy, Princeton, Princeton University Press, 2000.

Pons, A., El desorden digital. Guía para historiadores y humanistas, Madrid, Siglo XXI, 2013, p. 27.

Prakash, G., "Postcolonial criticism and History: subaltern studies", en Scheneider, A. y Woolf, D. (eds.), The Oxford History of Historical Writing. Historical Writing since 1945, Oxford, Oxford University Press, 2011, pp. 74-91.

Reddy, W., The Navigation of Feeling: A Framework for the History of Emotions, Cambridge University Press, Cambridge, 2001.

Rioux, J. P., "Historia del Tiempo Presente y demanda social", Cuadernos de Historia Contemporánea, 20 (1998), pp. 71-81.

— "Peut-on faire une histoire du temps présent?", en Chauveau, A. y Tétart, P., Questions à l'histoire des temps présents, Paris, Éd. Complexe, 1992, pp. 43-55.

Rodríguez-Magda, R. M., Mujeres en la historia del pensamiento, Barcelona, Editorial Anthropos, 1997.

Rose, S. O., What is Gender History?, Cambridge, Polity Press, 2010

Rosenwein, B. H., Emotional Communities in the Early Middle Ages, Cornell University Press, Ithaca and London, 2006.

Sanmartín, I., Entre dos siglos. Globalización y pensamiento único, Madrid, Akal, 2007.

Santana, J. M., "Globalization and Historiography" en Barros, C. y McCrank, L. (eds.), History under Debate. International Reflexion on the Discipline, New York, The Harworth Press, 2004. 
- "La historia en el fin de una época o el secuestro de Clío", en Barros, C. (ed.), Historia a Debate. Actas del I Congreso Internacional Historia a debate, T. I, Santiago de Compostela, Xunta de Galicia, 1995.

Schreibman, S., Siemens, R and Unsworth, J. (eds.), Companion to Digital Humanities, Oxford, Blackwell, 2004.

Scott, J., Gender and the Politics of History, Columbia University Press, New York, 1988.

Seefeldt, D. y Thomas, W. G., "What Is Digital History?", Perspectives on History, May 2009 $<$ https://www.historians.org/publications-and-directories/perspectives-on-history/may2009/intersections-history-and-new-media/what-is-digital-history>, (Consulta: 14-032016)

Soulet, J. F., L'histoire immédiate: historiographie, sources et méthodes, París, A. Colin, 2009.

Taibo, C., El decrecimiento explicado con sencillez, Madrid, Los Libros de la Catarata, 2011. Thébaud, F., "Entre parcours intellectuel et essai d'ego-histoire. Le poids du genre", Genre \& Histoire, 4, 2009, <http://genrehistoire.revues.org/697>, (Consulta: 10-08-2016).

Therborn, G., "Dialectics of Modernity: On Critical Theory and the Legacy of TwentiethCentury Marxism", New Left Review, 215, (Jan/feb 1996), pp. 59-81.

Thompson, E. P., Miseria de la teoría, Barcelona, Crítica, 1981.

Todorov, T., La memoria, ¿un remedio contra el mal?, Barcelona, Arcadia, 2009.

Traverso, E., El pasado, instrucciones de uso. Historia, memoria, política, Madrid, Marcial Pons, 2007.

Tubert, S. (coord.), Del sexo al género: los equívocos de un concepto, Madrid, Cátedra, 2003.

Tulsa, M. K., "Feminism, Ethics, and History, or What Is the 'Post' in Postfeminism?", Studies in Women's Literature, vol. 21, núm. 1 (Spring 2002), pp. 29-44.

Veyne, P., ¿Cómo se escribe la historia?, Madrid, Fragua, 1972.

Vigotsky, L., Pensamiento y Lenguaje, Madrid, Paidós, 1978.

Vilar, P., Memoria, historia e historiadores, Valencia, Universidad de Valencia, 2004.

Vries, P., "Global Economic History: a survey" en Schneider, A. y Woolf, D. (eds.), The Oxford History of Historical Writing. Historical Writing since 1945, Oxford, Oxford University Press, 2011, pp. 113-135. 